\section{Defensa de los derechos adquiridos: luchas y albures del ejercicio de la homeopatía en Colombia (1905-1950)}

\author{
Defending entitlement: \\ struggles and fate of the \\ practice of homeopathy in \\ Colombia (1905-1950)
}

\author{
Victoria Estrada Orrego ${ }^{i}$ \\ ' Investigadora, Grupo Producción, Circulación y Apropiación \\ de Saberes/Facultad de Ciencias Humanas y Económicas/ \\ Universidad Nacional de Colombia. \\ Medellín - Antioquia - Colombia \\ orcid.org/0000-0002-8872-3320 \\ vestradao@yahoo.com
}

Jorge Márquez Valderramai

ii Profesor, Departamento de Estudios Filosóficos y Culturales, Grupo Producción, Circulación y Apropiación de Saberes/ Facultad de Ciencias Humanas y Económicas/ Universidad Nacional de Colombia. Medellín - Antioquia - Colombia orcid.org/0000-0002-9677-3619 jmarquez@unal.edu.co

Recebido em 3 maio 2018

Aprovado em 1 fev. 2019.
ESTRADA ORREGO, Victoria; MÁRQUEZ VALDERRAMA, Jorge. Defensa de los derechos adquiridos: luchas y albures del ejercicio de la homeopatía en Colombia (1905-1950). História, Ciências, Saúde Manguinhos, Rio de Janeiro, v.26, n.4, out.-dez. 2019, p.1355-1372.

\section{Resumen}

El artículo analiza la práctica y el estatuto profesional de los homeópatas colombianos en el siglo XX, según las solicitudes de licencia de la serie "Teguas" del Archivo General de la Nación. Desde el contexto histórico del ejercicio de la medicina en Colombia, se estudia la práctica homeopática en su inserción en el debate entre medicina diplomada y medicina permitida. Ahí aparece la homeopatía como un campo subordinado a la medicina universitaria y los homeópatas como conjunto de practicantes no homogéneo ni organizado, pero caracterizado por compartir la lucha por el "derecho adquirido" a ejercer y por la defensa de un estatuto profesional mediante la judicialización constante de la reprobación oficial.

Palabras clave: historia; Colombia; estatus profesional; homeopatía; sistema médico.

\section{Abstract}

This article analyzes the practice and professional status of Colombian homeopaths in the twentieth century, based on applications for licenses in the "Teguas" series in the Archivo General de la Nación. Within the historical context of the practice of medicine in Colombia, it studies homeopathic practice within the framework of the debate between licensed and permitted medicine. In that context, the field of homeopathy was subordinate to university medicine and homeopaths were a group of practitioners who were neither homogeneous nor organized, but characterized by their shared struggle to become "entitled" to practice, and their advocacy of professional status through constant litigation against official reprimands.

Keywords: history; Colombia; professional status; homeopathy; medical system. 
$\mathrm{L}$ a gran difusión de la homeopatía comenzó en 1835 con la llegada a París de su fundador, Samuel Hahnemann, quien diferenció dos filosofías médicas con neologismos de su invención: homeopatía y alopatía. Desde ese momento existe divergencia epistemológica entre ambos sistemas. El principio base (similia similibus curantur) y la terapéutica (basada en dosis infinitesimales), pilares de la homeopatía, son contestados desde entonces por la medicina "científica" o "alopática" (Faure, 2002-2003, p.88).

La introducción de la homeopatía en Sudamérica se sitúa en la primera mitad del siglo XIX. Con diferencias notables, se ubica entre 1835 y 1850 para Colombia, Brasil y Argentina. De los tres, Brasil es el país de mayor continuidad temporal de la práctica homeopática, en su institucionalización y en su difusión, pues allí es evidente la persistencia de la transmisión del saber y de las asociaciones (Tarcitano, Waisse, 2016, p.783-788). En cambio, Colombia y Argentina se caracterizan por la discontinuidad y la dispersión de los esfuerzos por instituir la homeopatía. En los tres países, el liberalismo en auge en el siglo XIX permitió a la homeopatía un ejercicio poco controlado por el Estado y por la medicina oficial. Se publicaron revistas, se crearon asociaciones y se constituyeron escuelas por fuera de la institución universitaria (Tarcitano, Waisse, 2016, p.787-791; Guzmán, 1995, p.66-70). Esto permitió que se asumieran, no sin algunas resistencias, alopatía y homeopatía como dos sistemas médicos inspirados en principios filosóficos opuestos.

En Colombia, la creación de la primera escuela homeopática (1866) provocó una controversia entre representantes de ambos sistemas, atestiguada en tribunas impresas como La Homeopatía, La Gaceta Médica de Colombia y El Promotor de Barranquilla (Quevedo et al., 2010, p.25-31; Solano, 2006, p.313-326). Solo a partir de la década de 1870 se gradúan los primeros médicos en Colombia, gracias a la organización de la enseñanza en varias ciudades, pero de manera más clara en Bogotá y Medellín (Quevedo et al., 2010, p.8-24). La educación médica fue el ámbito institucional por excelencia de la medicina colombiana en el siglo XIX. Otros dos ámbitos, el de la higiene pública y el de los gremios médicos, tuvieron poco desarrollo. Sin embargo, el hecho de graduar médicos en universidades locales generó una nueva presión sobre el libre ejercicio de la medicina que había imperado (Márquez Valderrama, García, Delvalle Montoya, 2012, p.339-342).

Ha sido escaso el interés por los procesos de profesionalización en historia de la medicina en Colombia, es decir, aquellos mediante los cuales los practicantes de oficios relacionados con la medicina invocan y usan el concepto de "profesión" en su cotidianidad, en sus intentos por mejorar el estatuto laboral, en sus agremiaciones, en sus contiendas con la profesión dominante y en sus luchas por entrar en "la profesión". En esa historia se establece una narrativa donde la profesión no plantea problema, pues se la asume como una consecuencia natural de instituir la enseñanza. Es a esto a lo que el historiador John C. Burnham (1996, p.4) ha llamado "tradición iatrocéntrica en la escritura de la historia de la medicina". ${ }^{1}$ Esta narrativa ha caracterizado gran parte de la tradición historiográfica occidental de la medicina (p.8-9). Por fuera del enfoque iatrocéntrico se hallan estudios específicos que analizan la diferenciación entre ocupaciones y profesiones según relaciones de poder. En historia, cuando se trata de la "profesión", se sigue el derrotero de los sociólogos, quienes no han eludido los problemas históricos. 
La caracterización denotativa del concepto de profesión que la sociología ha construido y debatido desde los años 1950 hasta hoy señala los siguientes rasgos como los principales: actividad especializada que aporta subsistencia a quienes la practican con regularidad; reconocimiento mutuo, compartir rasgos de identidad, valores morales, un lenguaje esotérico y una formación específica; orientar sus actividades hacia lo colectivo mediante el servicio. Pero estos rasgos no alcanzan para diferenciar la profesión, pues son inherentes a muchas ocupaciones. Habría que añadir la característica del monopolio discursivo, político, económico y ético sobre la práctica y sobre las distinciones relativas al oficio. En la tradición occidental este monopolio ha sido concedido o avalado por el Estado y otorga una fuerte autonomía que incluye la autorregulación (Freidson, 1978, p.21-29).

Según el concepto de "campo" de Bourdieu, se pueden asumir alopatía y homeopatía como subcampos de la medicina. Lo que nos permite entender la medicina como terreno de luchas entre campos que tratan de diferenciarse como espacios sociales de acción y de influencia y que tejen distintas relaciones entre ellos, incluso a veces de dominación y subordinación. Esto complementa la definición de profesión de Freidson evocada arriba. El campo de la homeopatía, en Colombia, en el siglo XIX, había entrado en disputa epistemológica con la medicina universitaria en plena instauración en el periodo 18651870 (Quevedo et al., 2010, p.25-30). Sin embargo, en el siglo XIX, la homeopatía no se veía coaccionada desde el exterior por un campo dominante. Mostraremos que esa es la situación que comienza a perfilarse a partir de 1905, cuando por primera vez se regula, desde la medicina universitaria, el ejercicio de las artes médicas en Colombia.

Ahora bien, la escasa historiografía de la homeopatía en Colombia tampoco se ha ocupado del problema de la profesionalización. La profesión es tomada allí como un hecho dado. Esto quizás se explica por una exploración de archivos limitada, un escaso cotejo de fuentes y unos objetivos reivindicatorios (Sánchez Liévano, 2013, p.22-29).

La investigación para este artículo se basa en fuentes del Archivo General de la Nación (AGN), sección República, fondo Ministerio de Salud, serie Teguas. ${ }^{2}$ Esta serie se compone de un total de 3.937 expedientes de solicitudes de licencias para el ejercicio de la "profesión", clasificados en categorías, según la práctica del solicitante. Las más representativas son: odontólogos (3.148); homeópatas (555) y alópatas (176). Hay 58 expedientes de otras categorías. Las cantidades no pueden ser tomadas como dato significativo, pues se conocen las difíciles condiciones de conservación de los archivos en Colombia. Estos expedientes son una muestra de lo que las vicisitudes y esfuerzos de conservación dejaron sobrevivir. No son prueba de que un oficio médico se practicara más que otro. Aun así, la muestra es lo suficientemente rica como para permitirnos afirmar que la medicina diplomada llegaba a pocos lugares de Colombia y la medicina no diplomada hacía presencia en gran parte del territorio (Márquez Valderrama, 2015, p.91-102; Márquez Valderrama, Estrada Orrego, 2018, p.100-102). ${ }^{3}$ Nuestra muestra se compone de homeópatas que solicitaron licencias para ejercer en Colombia en el siglo XX.

La separación que usamos en alópatas y homeópatas la trae el archivo, organizado en parte por la Junta Central de Títulos Médicos (JCTM), creada en 1929. El historiador no puede ceñirse a esa división, pues, al leer los expedientes de homeópatas, salta a la vista, en algunos casos, la doble ocupación. 
El lector no encontrará aquí argumentos a favor o en contra de la medicina homeopática. El interés de la investigación es más bien contribuir a la historia de las profesiones médicas en Colombia, examinando el proceso de definición del estatuto de la homeopatía como parte de la historia de la normalización de la medicina universitaria. En ese contexto, la hipótesis central es que la homeopatía en Colombia, en la primera mitad del siglo XX, no actuó tanto como un sistema médico rival, sino como una de las prácticas subordinadas a las lógicas de legitimación de la medicina oficial.

\section{El estatuto profesional de los homeópatas}

El estatuto profesional de los homeópatas no podría precisarse sin detenerse en la medicina como profesión y como ocupación en la segunda mitad del siglo XIX. ¿En qué consistía ser médico en ese momento en Colombia? Si 1850 marca el comienzo de la libertad de oficio, de industria y de profesión como dogma en economía y en política, ${ }^{4}$ entre 1867 y 1871, las creaciones de dos nuevas universidades estatales abren las primeras fisuras a ese dogma. Ya en la década de 1870, funcionaban regularmente en Colombia al menos tres facultades de medicina. Empieza entonces un programa de profesionalización de médicos que se afianzó con la creación de las sociedades científico-médicas, la Sociedad de Medicina y Ciencias Naturales de Bogotá (1872) y la Academia de Medicina de Medellín (1887). En medio del liberalismo dominante a finales del siglo XIX se distinguía entre oficiantes de la medicina sin diploma y oficiantes legitimados por la universidad (Miranda, 1993, p.66-85). Aunque estos acontecimientos indican los albores de la profesionalización, las fuentes muestran que no se tradujeron en una consolidación y unificación inmediatas de la profesión de médico.

Aunque ya existieran facultades especializadas durante la segunda mitad del siglo XIX, el aprendizaje de la medicina era libresco, autodidacta, memorístico y con escasa socialización del saber (Márquez, García, Delvalle, 2012, p.340-341). Además, pesaba la tradición del apprenticeship (Pelling, 2017) es decir, formarse en el oficio o encontrar la vocación al lado de un hombre práctico, en la trastienda de una farmacia, en la casa de un médico o de un curandero. La formación parisina de varios médicos graduados y la institución del aprendiz se superponen durante este periodo y apenas a finales del siglo comienzan a ser refractarias una a la otra (Quevedo et al., 2004, p.57-71).

En el devenir de la profesionalización de la medicina en Colombia hay una discontinuidad en 1905, porque, desde el punto de vista legal, el estatuto profesional cambió a partir de la promulgación de la primera ley sobre el ejercicio de la medicina y profesiones afines (Colombia, 15 abr. 1905). A partir de ese momento se sucedieron numerosas reformas legislativas que abarcaron casi todo el siglo XX. No obstante, por largos años, la práctica médica y los oficios asociados a ella continuaron funcionando bajo una gran liberalidad, pues en cada nueva reforma se introducían salvedades que consentían el ejercicio (limitado) a los llamados "médicos permitidos" y "médicos licenciados". Los homeópatas en ejercicio nunca estuvieron exentos de estas regulaciones, aunque es evidente el trato especial que la ley les dio en todo el siglo XX.

Esa primera ley fue reglamentada en junio del mismo año mediante el decreto n.592, según el cual, además de los médicos graduados, podían ejercer la medicina "en lugares 
en donde no esté establecido ningún facultativo ... los individuos que tengan para ejercer licencia expedida por el médico titulado que esté establecido en la población más cercana" (Colombia, 19 jun. 1905). A este respecto, el artículo $4^{\circ}$ del decreto señalaba que quienes carecían de diploma de doctor y ejercían la profesión médica, podrían continuar ejerciéndola en su vecindad:

si se someten a un examen en un hospital, que verse sobre el diagnóstico y el pronóstico de la enfermedad de cuatro enfermos designados por un Consejo de examinadores nombrado por el Rector de la Facultad de Medicina ..., o por la Junta de Higiene más próxima al lugar de la residencia habitual del peticionario (Colombia, 19 jun. 1905).

Este decreto consolidó legalmente el recurso a una práctica ya habitual de atención de la población colombiana. Eran pocos los distritos que contaban con hospital y/o con junta municipal de higiene, pues la reinstitucionalización local apenas comenzaba tras la Guerra de los Mil Días (1902). Tener médico en la aldea era ubicarse en el camino de la civilización (López, 1934, p.337-338).

El trato especial que la ley daba a los homeópatas es evidente en el mismo decreto, pues podrían ejercer quienes tuvieran un diploma expedido por el Instituto Homeopático de Colombia (IHC) y los autorizados por un médico graduado.

Esta primera reglamentación confiere a los homeópatas sin diploma las mismas posibilidades y limitaciones que a los alópatas sin diploma, es decir, que pueden ejercer en lugares donde no practique un médico diplomado, siempre y cuando un médico graduado los certifique como idóneos para la medicina, nunca para la cirugía. Alópatas y homeópatas sin diploma forman así parte del conjunto de los médicos permitidos. Además, a partir de esta reglamentación, existen en Colombia tres clases de homeópatas: los permitidos, obligados a tramitar algún tipo de licencia; los nacionales poseedores de un diploma del IHC; y los homeópatas extranjeros, con o sin diploma. Aunque la homeopatía fue la única ocupación relacionada con la medicina a la que se reconocía mediante un diploma no universitario y al IHC se lo consideró como una organización de enseñanza con cierta autonomía respecto de las universidades reconocidas por el Estado, los homeópatas, desde el comienzo de la regulación de la profesión médica se vieron sometidos a la tutela administrativa y epistemológica de los alópatas.

En 1914 la situación jurídica del ejercicio de la medicina se mantenía casi inalterada. Los cambios en la legislación afectaron los procedimientos legales de otorgamiento de las licencias. A partir de la ley n.83 de ese año las otorgarían los gobernadores o los directores de instrucción pública de cada departamento. El artículo $6^{\circ}$ de esa ley seguía respaldando la tolerancia a los sin diploma. Muchos de ellos poseían una licencia, según lo estipulado en 1905. En cuanto a la libertad de ejercicio, ciertos matices aparecen. Los médicos sin diploma, pero con licencia, que no hubieran aprobado el examen solo podrían ejercer en lugares donde no hubiera "facultativos graduados", donde también actuarían legalmente quienes llevaran practicando la medicina al menos "cinco años antes de la expedición de [esa ley]", y que tuvieran permiso escrito de un médico diplomado. La licencia duraba hasta que un médico graduado se instalara en la localidad (Colombia, 23 nov. 1914). 
Parecen restricciones, pero son a la vez autorizaciones. Primero, los homeópatas autorizados, sin diploma, que hubieran aprobado ese examen, desde 1914, no tendrían restricciones geográficas. Sin embargo, el parágrafo del mismo artículo $6^{\circ}$ muestra que la vía del favoritismo podía legalizar, de hecho, lo que era ilegal de derecho: "las autoridades permitirán el ejercicio de la medicina (no de la cirugía), cuando así lo solicitaren por lo menos veinticinco vecinos honorables y la autoricen dos médicos graduados residentes en la localidad" (Colombia, 23 nov. 1914). El respaldo de la comunidad seguía siendo un factor decisivo para el otorgamiento o la prolongación de la licencia.

Mediante la ley n.67 de 1920, el Estado colombiano intentó estrechar el control del ejercicio de la medicina y profesiones afines. La novedad principal consistió en la creación, en cada departamento, de una junta examinadora de títulos médicos, entre cuyas funciones estaban la verificación de idoneidad y experiencia de aspirantes a ejercer la medicina y profesiones afines y el otorgamiento de licencias. A pesar de esta innovación y de requisitos más estrictos para licenciar, la política de tolerancia frente a los sin diploma se mantuvo (Colombia, 11 nov. 1920). Se expidió una nueva legislación reformadora (ley n.85 de 1922), pero preservó la permisibilidad. Sus novedades fueron las reglas para validar los diplomas extranjeros y las licencias de validez de dos años para estudiantes de medicina que hubieran cursado las materias (Colombia, 5 dic. 1922) (Figura 1).

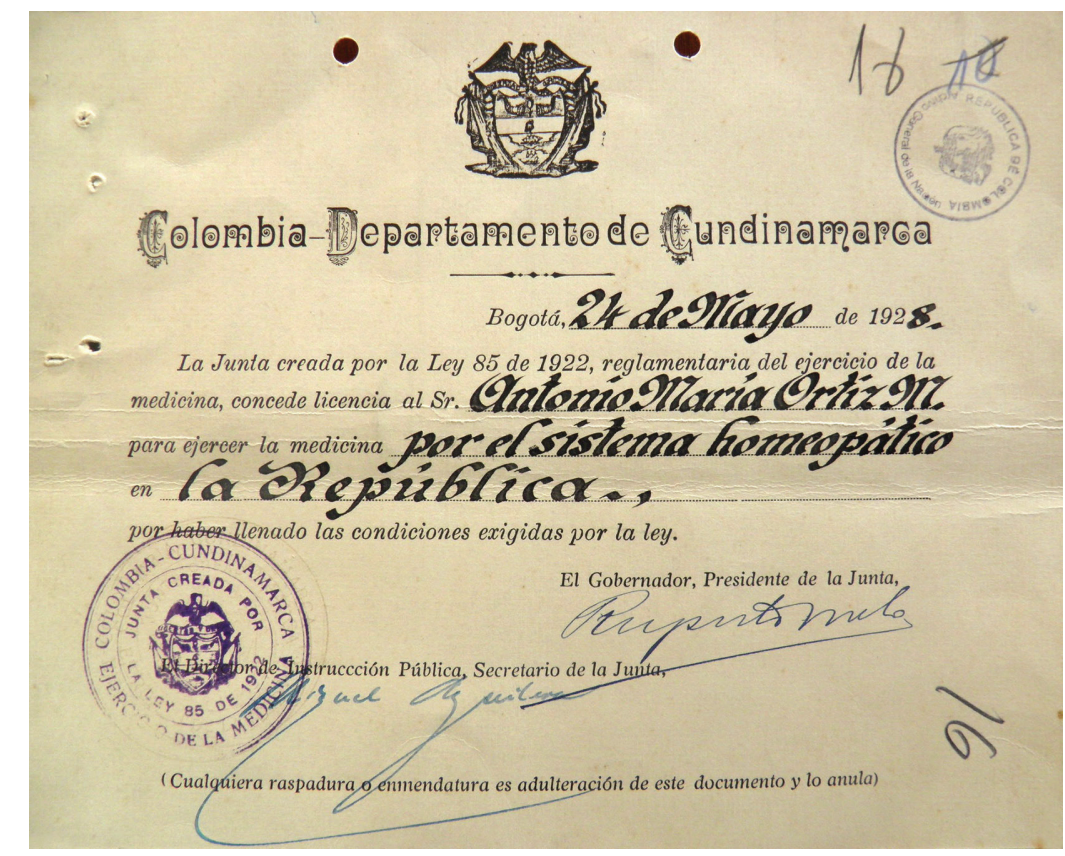

Figura 1: Licencia para el ejercicio de la medicina, Bogotá, 1928 (Fondo..., carpeta 3914, f.18)

Con la reforma de 1929, las disposiciones siguieron vigentes. Aunque la nueva legislación (ley n.35) intentó restringir más el proceso de aprobación y revalidación de las licencias, su novedad principal fue crear en Bogotá una Junta Central de Títulos Médicos (JCTM), “dependiente del Ministerio de Educación Nacional, compuesta de seis profesores de la 
Facultad de Medicina de Bogotá" (Colombia, 28 nov. 1929). Seguían funcionando las juntas departamentales de títulos médicos, pero con "un médico nombrado por la Academia Nacional de Medicina". La nueva ley estableció categorías de médicos: graduados nacionales, graduados extranjeros, nacionales graduados en un país extranjero, licenciados y permitidos (Colombia, 15 jul. 1930). Los homeópatas solo entran en la última categoría, lo que prueba la subordinación de su campo al de la medicina oficial alopática.

En las licencias, no siempre fueron claros los límites entre medicina alopática y homeopática. En las primeras décadas del siglo no era raro que los médicos obtuvieran certificados y licencias para ejercer por ambos sistemas, o licencias de médico homeópata con autorización para hacer uso de algunas drogas y procedimientos alopáticos. El caso de Rafael Bohórquez Rocha es un buen ejemplo. Bohórquez, quien ejercía la homeopatía en Cundinamarca desde 1906, fue certificado en 1912 por el médico diplomado Luis Cuervo Márquez, quien señala que desde años atrás el homeópata utilizaba "drogas y medicinas y que solo las usa en enfermedades de fácil tratamiento y de urgente atención médica", sin perjuicio para los pacientes. Puesto que en las poblaciones donde Bohórquez vendía sus drogas no había médico titulado, Cuervo avaló su ejercicio profesional (Fondo..., 1905-1959, carpeta 3310, f.33-34). Aval ratificado socialmente en 1916 con un memorial firmado por 92 varones que declararon: "hace más de 10 años Bohórquez ejerce la medicina homeopática y alopática con resultados satisfactorios", y que no habiendo médico graduado, sus servicios y su botica son indispensables (Fondo..., 1905-1959, carpeta 3310, f.38-39). Mientras los alópatas no vieran comprometidas sus conquistas del monopolio médico, no cuestionaban el doble ejercicio de los homeópatas. De hecho, en 1919, la gobernación de Cundinamarca certificó que Bohórquez llevaba más de 15 años ejerciendo la medicina alopática (Fondo..., 1905-1959, carpeta 3310, f.35).

Por la ley n.35 de 1929 se intentó, no siempre con éxito, eliminar las posibilidades de este doble ejercicio. Esta ley obligó a Bohórquez a presentar pruebas de su actuar como homeópata: un memorial firmado por 17 notables, certificando que ejercía solamente por el sistema homeopático y que se limitaba a suministrar "glóbulos"; ocho declaraciones de 1930 certificando 15 años de ejercicio de la homeopatía; varios testimonios de pacientes que afirmaron haber sido curados, con homeopatía, de fiebre tifoidea, una década atrás; y un certificado de 1931 del alcalde de Vergara acreditando su función de médico legista para la alcaldía y el juzgado (Fondo..., 1905-1959, carpeta 3310, f.15-24). Luego del fallo del Consejo de Estado a favor de los homeópatas, en octubre de 1931, y tras la evaluación de esas pruebas, la Junta de Títulos médicos de Cundinamarca le otorgó, en 1932, la licencia nacional para el ejercicio de la homeopatía. En 1937, Bohórquez solicitó la revalidación de su licencia según los requisitos exigidos por el decreto n.2.736 del año anterior (Colombia, 18 nov. 1936). Es un hecho notable que incluyera en su documentación un certificado del Concejo Municipal de Nocaima, señalando haber ejercido la homeopatía en ese lugar con "filantropía y acierto digno de encomio", que ha sido "un verdadero recurso para el municipio", en sus funciones de "médico del Hospital" y de "encargado de la misión sanitaria municipal" (Fondo..., 1905-1959, carpeta 3310, f.10). Según el artículo $6^{\circ}$ del decreto n.986 de 1932, ningún homeópata podía ejercer la medicina por el sistema alopático, ni intervenir en operaciones quirúrgicas (Colombia, 11 jun. 1932). ¿No eran privativos de 
los médicos alópatas esos cargos públicos? ¿No constituía el desempeño de ellos prueba para abrirle un sumario policial por ejercicio ilegal de la medicina? Puesto que no existía en Nocaima médico graduado que reclamara derechos, y como además se contaba con el respaldo de la administración municipal, la JCTM le revalidó la licencia de homeópata. El derecho adquirido a ejercer la medicina homeopática, defendido por Bohórquez, le fue respetado décadas más tarde, como lo muestra la solicitud que elevó en 1959 ante el Consejo de Práctica Profesional para que le expidieran una copia de su última licencia (Fondo..., 1905-1959, carpeta 3310, f.43-44).

Otro caso de doble ejercicio de la medicina se detecta en el expediente de Arturo García, quien ejercía en el departamento del Tolima. García tenía licencias de 1915, 1919 y 1920 otorgadas por la Dirección de Instrucción Pública Departamental para ejercer como homeópata y "en la especialidad helmintológica". ¿A qué se refiere esta última "especialidad"? El padre de García, quien fuera médico diplomado, compró una fórmula antihelmíntica a un médico mexicano y, en 1908, la transmitió a su hijo. Fue gracias al uso de esa fórmula alopática que Arturo García obtuvo las licencias no homeopáticas (Fondo..., 1905-1959, carpeta 3503, f.24, 31). García llega incluso a defender su doble ejercicio en el proceso de revalidación de la licencia que comenzó en 1930, cuando solicitó a la JTM del Tolima que no le prohibieran el ejercicio de la homeopatía y que le concedieran permiso para continuar con "el ejercicio de la medicina - no de la cirugía - en las poblaciones donde no se hayan establecido médicos diplomados" (Fondo..., 1905-1959, carpeta 3503, f.47). Esto significa solicitar una doble licencia. En ese proceso de revalidación, un médico con diploma se opuso a la solicitud argumentando que en el municipio ejercían dos médicos graduados y que el permiso para practicar la "especialidad de helmintología" era insólito, máxime cuando esa especialidad ni siquiera existía en la medicina universitaria colombiana (Fondo..., 1905-1959, carpeta 3503, f.29). Estos alegatos no parecen surtir efecto, pues en 1937, García presentó nuevos testimonios de médicos graduados para certificar su ejercicio como homeópata desde tiempo atrás, e incluso uno de ellos menciona que llevaba dos años trabajando con García en medicina y cirugía y elogia su "preparación científica", experiencia y escrupulosidad (Fondo..., 1905-1959, carpeta 3503, f.11-13). Desde 1905, el ejercicio de la cirugía quedó proscrito a los médicos permitidos. Así que este último documento hubiera podido bastar como prueba de que García se extralimitaba en sus funciones de homeópata, pero no fue el caso. Si es usual encontrar en los expedientes certificados de idoneidad presentados por otros médicos homeópatas. ${ }^{5}$ El proceso de García pone en evidencia cómo, en ciertas ocasiones, los médicos alópatas estuvieron a favor del doble ejercicio de la medicina. No obstante, y acogiéndose a la normativa en vigor en 1938, la JCTM le revalidó la licencia de homeópata (Fondo..., 1905-1959, carpeta 3503, f.70) y le anuló la licencia de "especialidad helmintológica".

Bohórquez y García atraviesan distintas coyunturas y cambios en la reglamentación, conservando su estatuto de homeópatas permitidos. Sus casos muestran cierta porosidad de la frontera epistemológica entre homeopatía y alopatía, a la vez que evidencian la subordinación legal del primer campo al segundo. Pero también prueban la prolongada tolerancia de la medicina oficial colombiana frente a los médicos permitidos. 


\section{El debate sobre un derecho adquirido: 1930}

El 29 de agosto y el 13 de septiembre de 1930 dos abogados, apoderados de dos grupos de homeópatas, presentaron ante el Consejo de Estado sendas demandas de derogación de varios artículos del decreto ejecutivo n.1.099 del 8 de julio de ese año. Las demandas denunciaban que el decreto era violatorio de la Constitución Nacional y de la ley n.35 de 1929, que reglamentaba, y que lesionaba derechos civiles adquiridos. Ambas fueron admitidas y el Consejo de Estado, mediante sentencia n.1.030 de 1931, se pronunció a favor de los demandantes, quienes argumentaban que no se podía, intempestivamente, negar el derecho adquirido a ejercer la medicina ni aplicar la ley de manera retroactiva a quienes habían sido reconocidos legalmente como homeópatas. Es decir, los poseedores de diplomas del Instituto Homeopático de Colombia, validados entre junio de 1905 y noviembre de 1929, y que además habían sido autorizados a ejercer sin restricciones temporales ni espaciales (Colombia, 1931). Por otra parte, la ley n.35 de 1929 confirmó la autorización de ejercicio a todos los homeópatas permitidos y se la negaba solamente a los que no pudieran probar, mediante declaraciones de testigos, haber ejercido durante los cinco años anteriores a su promulgación. El nuevo decreto introdujo restricciones injustas para los homeópatas.

Para la comprensión del estatuto de los homeópatas y de las condiciones de su ejercicio es necesario detallar las motivaciones y argumentos de ambas demandas. Para ello nos apoyamos en un artículo de un diario nacional (Sarmiento, 1 ago. 1930), en el cual un conocido homeópata, Manuel Sarmiento Castillo, ${ }^{6}$ da su opinión sobre el decreto n.1.099. Critica, primero, la actuación de la Academia Nacional de Medicina de Colombia (ANMC) como órgano consultivo del gobierno para la legislación del "ejercicio de las profesiones médicas y algunas otras". Y pregunta por qué no se consultó a la Academia de Jurisprudencia. ${ }^{7}$ Subraya irónicamente que para el estudio de la ley, el presidente y la ANMC se tomaron ocho meses, y satiriza la actuación de esa entidad como cuerpo consultivo: "someten a los ángeles de los hospitales la decisión de los negocios que tocan la ciencia de Justiniano" (Sarmiento, 1 ago. 1930). El argumento de Sarmiento es que de la misma manera como los abogados no deberían estar autorizados para pronunciarse como expertos en medicina, los médicos no deberían estarlo para pronunciarse en cuestiones jurídicas. Denuncia como inconstitucional el monopolio profesional que persiguen los alópatas, organizados en instituciones estatales, académicas y gremiales:

En el decreto ... flota como un corcho sobre aguas letales, el pensamiento de que fuera de la facultad de medicina no hay salvación; y ese ideal pudiera realizarse conforme al propósito exterminador en que se inspira, si no mediara la pequeña circunstancia de que, constitucionalmente, ni el mismo Congreso puede llevarse de calle ningún fuero legítimo (Sarmiento, 1 ago. 1930).

Sarmiento (1 ago. 1930) llama a la búsqueda de ese monopolio "pasión académica" o "gusano roedor". El artículo n.14 de dicho decreto exigía a los homeópatas "permitidos" demostrar treinta años de ejercicio. Para Sarmiento, la "pasión alopática" pretendía "acabar con los homeópatas de modo definitivo al limitar su número, de los autorizados para ejercer, únicamente a los que tengan 30 años de práctica". 
También indigna al polemista la limitación geográfica del ejercicio a los homeópatas "permitidos", ${ }^{8}$ contenida en el mismo artículo. Arguye Sarmiento (1 ago. 1930): "la honorable academia fija los linderos: en los lugares 'donde no haya médico titulado'. Es principio universal de jurisprudencia el de que, donde el legislador no distingue, a nadie le es dado distinguir". Según Sarmiento, la Academia ahí suplanta al poder legislativo. Los otros puntos que denuncia son el impuesto de cien pesos que se pretendía cobrar por cada licencia expedida y la prohibición de recetar en lengua extranjera. Según él, esta última norma perjudicaba a los homeópatas y farmaceutas homeopáticos porque escriben sus prescripciones en latín. Las restricciones propuestas por la ANMC contra los homeópatas (pecuniarias, geográficas, temporales, corporativas) solo buscaban el interés de esa corporación, "sin que importe para nada el atropello que pueda hacer de derechos ajenos legítimamente adquiridos" (1 ago. 1930). E invoca el artículo n.31 de la Constitución Política de Colombia de 1886: "Los derechos adquiridos con justo título con arreglo a las leyes civiles por personas naturales o jurídicas, no pueden ser desconocidos ni vulnerados por leyes posteriores" (1 ago. 1930).

Sarmiento (1 ago. 1930) esgrime como argumento en favor de su campo el frecuente tránsito de pacientes de la alopatía a la homeopatía. Se trata de circunstancias verificables en los numerosos testimonios de pacientes que acompañan las solicitudes de licencias de la serie Teguas. Presentamos un ejemplo de estos "clientes perdidos definitivamente para los consultorios alopáticos". El 8 de enero de 1930 Carmen González de Moreno declara sobre su hija:

sufría ataques epilépticos, la hice ver de 21 médicos de reconocida competencia como los doctores Pompilio Martínez y el Dr. Abraham Salgar, no habiendo logrado que estos la curaran, agravándose diariamente más hasta el punto de haberse enloquecido ..., la puse en manos del señor Silvestre Buitrago quien por medio de drogas homeopáticas la curó radicalmente en un término de dos meses, y digo radicalmente porque después de esa fecha, o sea de siete años a esta parte, no le han vuelto a dar (Fondo..., 19051959, carpeta 3311, f.20-21).

En el siglo XIX, el debate de la homeopatía era filosófico, médico y científico (Guzmán, 1995, p.69-72). Según nuestros hallazgos, no podía tratarse de un debate jurídico porque en esa época no existía regulación del ejercicio de la medicina en Colombia. Hemos constatado que desde cuando se expide la primera reglamentación (1905), el estatuto de los homeópatas recibe un tratamiento legal especial, pues entre los médicos permitidos serán los únicos reconocidos mediante un diploma de un instituto privado no avalado por el Estado. Además, después de la reglamentación de 1914 se volvió una realidad de hecho el que pudieran ejercer en el ámbito nacional. Lo que se transformó en situación de derecho a partir de 1930. En cambio, varias normas, incluido el decreto n.1.099, constreñía a los permitidos alópatas a ejercer en un municipio con la condición, además, de que en ese lugar no estuviera ejerciendo un médico graduado, pues eran considerados los directos competidores de la medicina oficial.

El ponente de la sentencia n.1.030 muestra la concepción de la medicina colombiana según la cual alopatía y homeopatía son dos sistemas médicos diferentes. Dos médicos, representantes a la Cámara, ponentes de la ley n.35 de 1929, argüían en este sentido: 
que las dos escuelas que tratan el arte de curar, la alópata y la homeópata, tienen iguales derechos para vivir; ... hoy en día solo se trata del arte de curar y no se mira cuál sea el sistema que lleve a la verdad, si el alópata o el homeópata, ya que es la experiencia adquirida en los laboratorios la que es maestra en estas cuestiones (Colombia, 1931).

Si bien es cierto, tal y como se anunció en la prensa nacional (El Consejo..., 6 nov. 1931; Los homeópatas..., 9 dic. 1931), que los médicos homeópatas ganaron la batalla contra el decreto n.1.099, su estatuto profesional era frágil. La obtención de licencias era en ocasiones un calvario para los peticionarios. La JCTM se reunía de forma esporádica y a veces pasaban varios meses sin que lo hiciera. Las respuestas tardaban meses o años. La documentación entregada podía traspapelarse en Bogotá y esto los obligaba a reiniciar el proceso. En ocasiones, las licencias se otorgaban erradamente para un departamento específico y el solicitante apelaba para que se la ampliaran al territorio nacional. Algunos tenían licencia pero no aparecían inscritos en las listas de médicos permitidos, lo que los obligaba a solicitar, cada vez que cambiaban de municipio, una nueva copia de la licencia. Era necesario revalidarlas y las vicisitudes del proceso se multiplicaban en manos de los funcionarios del campo de la alopatía cada vez más reacios al libre ejercicio de los homeópatas.

Sin embargo, la lógica de los favoritismos seguía imperando y había casos menos complicados, como el del ciudadano español Juan José Balaguer Gilet quien, desde 1927, ejercía la homeopatía en Bogotá. Aunque al presentar su solicitud de licencia, Balaguer no poseía diploma, ni colombiano ni extranjero, contó con el apoyo de médicos homeópatas colombianos, entre ellos el presidente de la Asociación Nacional de Medicina Homeopática (Fondo..., 1905-1959, carpeta 3460, f.15-16). La rapidez con la que se le resolvió la solicitud de licencia contrasta con las complicaciones y la lentitud en las diligencias de los demás médicos permitidos colombianos, quienes constantemente se quejaban del trato que recibían por parte de los burócratas de la JCTM. Esta excepción muestra que los trámites eran obstáculos perfectamente controlables por la burocracia médica.

\section{Homeopatía, cientificidad y extralimitación de funciones}

No se encuentra normativa que explícitamente prohíba a los médicos permitidos (incluidos los homeópatas) el desempeño de cargos públicos municipales como médico oficial, médico escolar, inspector de higiene, subdirector de higiene, médico del hospital. Quizás la ausencia de prohibición manifiesta explique el hallazgo en los expedientes de algunos certificados de idoneidad en los que se informa que el homeópata sirvió como médico legista municipal, médico escolar, que atendía pacientes en el hospital o que participaba en campañas sanitarias. Si hasta los años 1920 esto era posible, los alegatos en contra se vuelven recurrentes en los años 1930. Los casos en los que un homeópata permitido fungía como médico oficial se presentaban casi siempre en municipios donde no había médico graduado o licenciado. La autoridad oficial nombraba entonces al homeópata y producía así el doble ejercicio que le resultaba conveniente. Es el caso del homeópata Arturo García quien en 1916 fuera nombrado médico legista municipal en Purificación y en 1919 fue delegado por la Dirección Departamental de Higiene del Tolima para coordinar 
la comisión sanitaria municipal que debía contrarrestar una epidemia de disentería en Miraflores (Fondo..., 1905-1959, carpeta 3503, f.3, 16-19).

La controversia surge cuando un funcionario, un médico graduado o un farmaceuta en ejercicio, se oponen a la comisión, alegando que estas funciones corresponden solo a los diplomados. En 1931, el homeópata Eduardo Tribiño Sáenz declara que por poseer licencia de farmaceuta, el alcalde de Neira (Caldas) le ha montado una "guerra" a su actividad, ya que él también posee botica en ese lugar. Esto ha llevado al funcionario a la "envidia y al abajamiento del interés pecuniario" de la profesión. Tribiño solicita además que se respeten los certificados de defunción que él expide (Fondo..., 1905-1959, carpeta 3739, f.3). Cinco años más tarde y mientras ejercía en Santuario (Caldas), se vio envuelto en una indagatoria policial al ser acusado de recetar a dos policías en el Hospital de Caridad e inyectar un medicamento a uno de ellos. En el proceso, el médico oficial de Santuario declaró que Tribiño, aunque ejerciera, no era médico; que había sido nombrado inspector de sanidad por el concejo; que en ocasiones atendía pacientes en el hospital, sin demostrar los conocimientos científicos para ello; además de no poseer título universitario, tampoco era médico licenciado (Fondo..., 1905-1959, carpeta 3739, f.20-25). Tribiño apeló la sanción impuesta, arguyendo persecución. Dijo tener licencia y relató que llegó al municipio porque sería nombrado médico escolar con funciones de subdirector de higiene y asistencia públicas. Este nombramiento no se efectuó y, por sus necesidades económicas (padre de ocho hijos), el gobierno municipal decidió nombrarlo inspector de sanidad. Explicó que atendió a dos policías en respuesta a un llamado del síndico del hospital, por ausencia del médico oficial. En el proceso, en marzo de 1937, la DDH de Caldas solicitó a la JCTM claridad sobre las actividades permitidas a los médicos homeópatas en municipios donde había médicos graduados. Esa junta respondió que podían ejercer en el territorio nacional solo la medicina homeopática, que no podían atender enfermos en un hospital, que podían recetar, pero que no podían aplicar inyecciones y no podían desempeñar cargos públicos (Fondo..., 1905-1959, carpeta 3739, f.29-30). En 1939 se le abrió a Tribiño un proceso por ejercicio ilegal de la medicina. El motivo fue haber fijado una placa con la palabra doctor en la puerta de su consultorio (Fondo..., 1905-1959, carpeta 3739, f.13-15). El fallo le fue adverso y no se le renovó la licencia de médico homeópata. En abril de 1941 apeló, pero la JCTM confirmó el fallo con el argumento de que Tribiño había actuado en extralimitación de su licencia de homeópata (Fondo..., 1905-1959, carpeta 3739, f.71-73).

Otro ejemplo de extralimitación del ejercicio de la homeopatía lo encontramos en el expediente de Rafael Cruz Briceño. Cruz Briceño tenía licencia para ejercer como homeópata desde 1922 y solicitó revalidación en 1933. También gozaba de licencia de farmacéutico desde 1931. Le fue renovada la licencia de homeópata. Sin embargo, en 1943, se le abrió una investigación por homicidio. En el proceso se intentó establecer si como médico homeópata estaba autorizado para realizar fricciones. La Federación Médica Colombiana lo acusó de anunciarse como médico, sin indicar que era homeópata, en un volante publicitario, ilustrado con una imagen del Arcángel San Gabriel, considerado en algunos países el patrono de los médicos (Figura 2). Todas las licencias señalaban explícitamente que los peticionarios no podían usar el título de doctor y podían ser canceladas si las empleaban de forma inmoral o fraudulenta o si ejercían la profesión por un sistema distinto 
al homeopático (Fondo..., 1905-1959, carpeta 3305, f.19). Por ello se solicitó a un médico alópata que examinara las drogas y artículos del "Consultorio y farmacia homeopática Cruz Briceño" (Fondo..., 1905-1959, carpeta 3321, f.41) y que cotejara su libro de fórmulas. Este perito declaró la existencia de productos de uso exclusivo de alópatas e informó que el local y el consultorio no reunían las condiciones higiénicas. Nada prueba que la investigación prosperara. De hecho, en 1945 se le revalidó a Cruz Briceño la licencia de homeópata para ejercer en la zona bananera, con la advertencia de que no podía usar el título de doctor y que si contraviniere se le podría cancelar la licencia (Fondo..., 1905-1959, carpeta 3321, f.40).

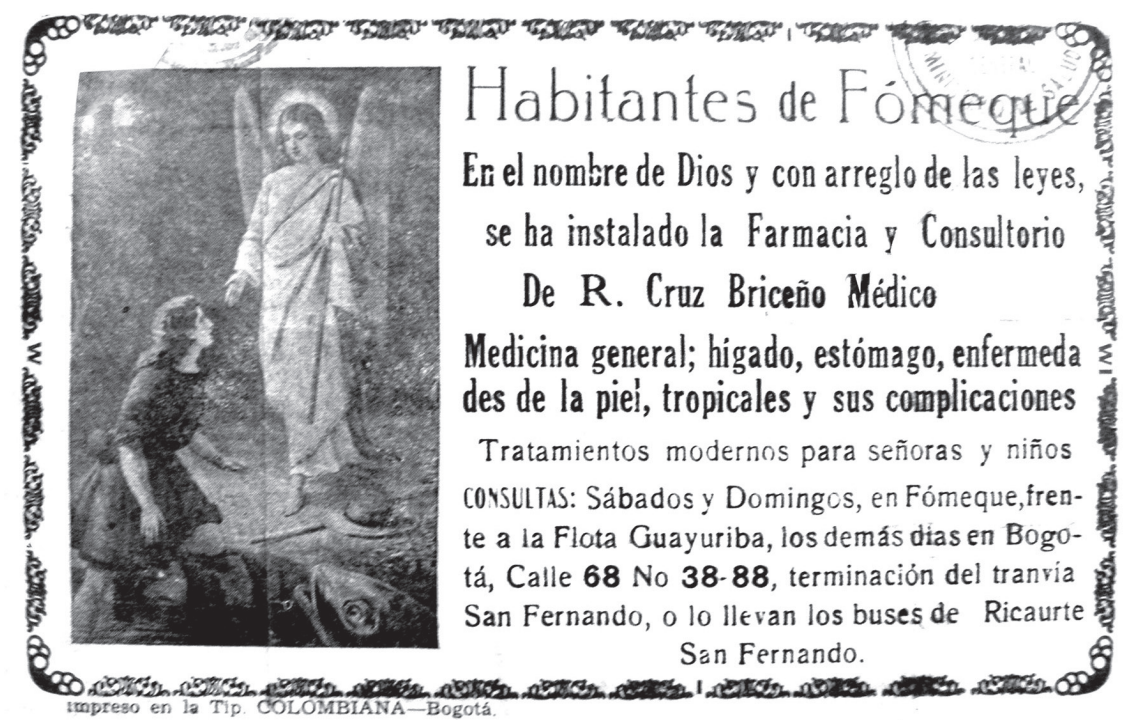

Figura 2: Publicidad de R. Cruz Briceño, médico (Fondo..., carpeta 3321. f.34)

Si bien hay cierta tolerancia oficial hacia los homeópatas en los años 1940, es evidente que se les comienzan a imponer restricciones en sus amplias funciones.

Anular la licencia de los médicos homeópatas no era en todos los casos una tarea sencilla. La administración pública y la corporación gremial de los médicos, la Federación Médica Colombiana (FMC) lo intentaron sin éxito en varias ocasiones, en los años 1940. Creada en 1936, la FMC defendía el ejercicio de la profesión médica nacional ante la llegada de médicos extranjeros y la proliferación de teguas y charlatanes. El expediente de Pedro Escobar Wiesner pone en evidencia que las pruebas testimoniales de pacientes o de particulares, como documentos para acreditar la pericia profesional, comienzan a ser criticadas. Muestra también los ataques de los médicos diplomados contra el derecho adquirido de los homeópatas. Deja ver las denuncias contra los homeópatas como una amenaza a la salud pública y la impotencia de la medicina oficial para anular sus licencias.

Escobar, con título del IHC de 1914, presenta testimonios de pacientes en 1919, 1920 y 1921, certificando los buenos resultados de su práctica profesional. Algunos de ellos señalan los servicios del homeópata como menos costosos que los alópatas; el haber sido desahuciados por varios médicos alópatas; y que la práctica de Escobar era intachable (Fondo..., 1905-1959, carpeta 3325, f.22-35). En 1939 se le revalidó la licencia para ejercer 
en el territorio nacional y se publicó la resolución en el Diario Oficial (Fondo..., 19051959, carpeta 3325, f.46). En 1944, tuvo lugar un intercambio epistolar entre la Dirección Municipal de Higiene (DMH) de Bogotá, la FMC, la JCTM y el Ministerio de Trabajo y Previsión Social relativo a la petición que hizo la DMH para que se le negara a Escobar "el derecho a recetar y en consecuencia el de expedir certificados de defunción", fundando la petición en la ignorancia que el sujeto exhibe en los certificados (Fondo..., 1905-1959, carpeta 3325, f.49). En uno de ellos el diagnóstico señala "infección tífica e imbación [sic] de lombrices". La DMH estaba obligada a registrar sus certificados de defunción, puesto que Escobar estaba inscrito como médico homeópata. Por la mala calidad de estos, algunos médicos diplomados expresaron: "se [teme] por la vida de las personas que acudan a él para que las trate y además desorientan los trabajos de la epidemiología en esta ciudad". ${ }^{9}$ En apoyo a la DMH, la federación solicitó a la JCTM establecer "un buen procedimiento para cancelar licencias y que se haga uso de ello enérgica y perentoriamente mientras no se disponga de un arma mejor" contra quienes cometan infracciones a la ley n.67 de 1935, todo ello en defensa del "honesto y científico ejercicio de la profesión" (Fondo..., 1905-1959, carpeta 3325, f.47). El gremio médico debate al respecto con el ministerio, que exige un sumario establecido para comprobar la infracción y sugiere a la FMC ayudar para que el gobierno llene ese vacío jurídico. La JCTM creó una comisión evaluadora del expediente. Esta comisión señala que las declaraciones que presenta Escobar no tienen valor alguno, pues son de particulares "sin ninguna vinculación técnica ni científica con instituciones médicas u organizaciones profesionales"; además, "especiales condiciones de preparación profesional o pericial no pueden acreditarse con simple prueba testimonial" (Fondo..., 1905-1959, carpeta 3325, f.54). Critican también la calidad de sus certificados de defunción: "constituyen verdaderos absurdos científicos que dan la idea más desfavorable sobre la persona que los redactó y firmó"; por otra parte, "el uso equivocado y lamentable" que hace de la nomenclatura médica y su mala ortografía revelan que no sólo es un "lego e ignorante en el campo de la medicina" sino también que tiene una pobre instrucción. Con el argumento de la responsabilidad social de velar por la salubridad pública, la comisión solicita revocar la licencia a Escobar (Fondo..., 1905-1959, carpeta 3325, f.55-56). El intercambio epistolar continúa en 1945, sin que a Escobar se le haya cancelado la licencia. Para hacerlo, tendrían que probarle extralimitación en sus funciones como homeópata. Gracias a la licencia concedida en 1939, estaba habilitado para firmar certificados de defunción, aunque fueran de dudosa calidad. En octubre de 1945, el Ministerio de Educación Nacional le solicita a la JCTM que responda a la apelación interpuesta por Escobar (Fondo..., 1905-1959, carpeta 3325, f.59). La documentación no deja ver si la licencia fue revocada. Aun así, los argumentos científicos y epistemológicos de la autoridad médica vienen a reforzar las razones de la lucha por el monopolio de una medicina basada en evidencias y estadísticas y en un lenguaje médico especializado. Se unen los discursos de la salud pública - como práctica política basada en la ciencia - , los de la institución universitaria y los de la agremiación médica en el afianzamiento del monopolio de la medicina oficial. Esto debilita al campo de la homeopatía y lo muestra aún más subordinado al campo de la alopatía. 


\section{Consideraciones finales}

Tras la promulgación de las primeras regulaciones del ejercicio de la medicina (1905), el debate sobre la homeopatía comienza a ser sobre todo jurídico, aunque se mantiene la discusión sobre la competencia científica y profesional. Se trata de un debate desigual entre dos campos: alopatía y homeopatía. Los homeópatas, en su calidad de médicos permitidos, están por fuera del establecimiento que los controla, compuesto por alópatas con título universitario. La alopatía aparece como una profesión establecida y con autonomía.

Sobre esto último hay que precisar que toda definición de un concepto tiene algo de ideal y de abstracto. La de profesión con la que comienza este artículo no escapa a ello. Freidson (2001) argumenta que ella debe hacerse según el contexto espacio-temporal, histórico, de cada sociedad donde se estudie el fenómeno. Y va más allá: "la profesión debe abordarse como una entidad empírica sobre la que hay poca base para generalizar, ya que no se trata de una clase homogénea o una categoría conceptual lógicamente exclusiva" (p.39).

Para volver a lo empírico, la medicina diplomada colombiana de la primera mitad del siglo XX se hallaba en vías de adueñarse de dos tipos de monopolio: el discursivo y el económico. El primero se apoya en tres pilares: el científico, que les permite controlar enteramente la nueva forma de transmisión del saber, la universidad, opuesta a la tradicional institución del aprendiz; el político-jurídico, recibido del Estado para decidir quién es médico, qué es un acto médico, cuáles son las funciones sociales de la medicina y quiénes pueden ejercerlas; y el ético que los médicos se abrogan desde el siglo XIX al apuntalarse en la ideología del médico sacerdote con vocación "natural" de asistencia, lo que los convierte, según ellos, en poseedores exclusivos de la conducta y la actitud éticas.

Para la medicina universitaria, el monopolio económico (o de la práctica) es el menos consolidado y quizás el más disputado. Esto es evidente en la interdicción legal de trabajar, impuesta eventualmente a los permitidos y en los pleitos contra ellos cuando había médico diplomado en un lugar. Las querellas por el monopolio de la práctica muestran que la búsqueda del monopolio universal (ético, científico, político y económico) por parte de la alopatía es un proceso de normalización de las artes médicas del cual debían ser excluidos los oficiantes irregulares. Pero una cosa es lo que dicta el derecho y otra lo que provocan los hechos. El intenso debate, de más de cinco décadas, las salvedades y las reformas en las legislaciones, los pleitos jurídicos y las miles de solicitudes para ejercer la medicina sin diploma forman el cuerpo de evidencias de ese proceso de normalización que Bourdieu (2000, p.210-211) explica como estandarización y universalización de lo dominante mediante reglas explícitas.

Esta medicina alopática, en vías de consolidar un monopolio de las artes médicas, es lo que llamamos la medicina oficial. Frente a ella, la práctica de la homeopatía, tal y como nos la muestra el archivo, se puede definir como una ocupación en plena lucha por ser reconocida como profesión, pero cuyo estatuto no solo está subordinado a la medicina oficial, sino que está siempre cuestionado y vigilado mediante el acto legal y administrativo de la renovación de licencias, delegado por el Estado en los alópatas. En el sistema dominante los homeópatas están en el campo débil, el de los oficiantes sin diploma. De ahí que se vean tantas veces obligados a atacar el establecimiento mediante recursos jurídicos. Por eso, en 
Colombia, la idea de la homeopatía y la alopatía como dos sistemas médicos rivales es solo una apariencia, pues, en realidad, el uno permanece subordinado al otro. Subordinación evidente en el constante recurso a las recomendaciones. Las cartas de apoyo de notables, vecinos, clientes, médicos graduados y profesores de medicina, las pruebas de una larga experiencia, la aceptación por parte de la comunidad eran aspectos propios de un habitus social y político de reconocimiento imperante en el siglo XX. Hacen parte de las formas y las retóricas de legitimación del ejercicio médico de los permitidos, a las cuales no escapan los homeópatas. Su reconocimiento profesional, como el de los demás médicos permitidos, es provisional, está siempre en entredicho. El de los alópatas aparece como natural, es decir normalizado definitivamente por la posesión del diploma.

En el periodo estudiado se ve funcionar una doctrina clásica del derecho adquirido como principio de originalidad de derechos que el poder público debe proteger a partir de la confianza legítima de los particulares en el actuar honesto del Estado. Una vez otorgado, se confía en su prerrogativa. Pero el Estado podía interrumpir esa confianza, ya fuera con el argumento de proteger un bien jurídico de rango superior o mediante actos legislativos. Interpretaciones de la norma podían invalidar o revalidar el derecho adquirido. En el caso de los homeópatas colombianos se intentó suprimir ese derecho al ejercicio mediante cambios legislativos que buscaban detener el ingreso de nuevos beneficiarios. De ahí que, con su débil capital simbólico, los homeópatas recurrieran una y otra vez a la judicialización del sistema para conservar su derecho.

El estatuto de los homeópatas se puso de nuevo en vilo en 1950 cuando se promulgó el decreto n.2.597 en cuyo artículo 9 se suspendía el apartado de la ley n.35 de 1929 que permitía ejercer a quienes tuvieran diploma del IHC y a quienes, careciendo de diploma, demostraran el ejercicio de la homeopatía durante cinco años (Colombia, 18 ago. 1950). Con la entrada en vigencia de este decreto, la homeopatía pierde legitimidad profesional y comienzan nuevas batallas por la legitimación mediante la demanda de inexequibilidad de ese decreto.

En ese nuevo escenario de lucha por un estatuto profesional, los discursos de defensa de la homeopatía se vuelven más radicales en cuanto a la autonomía: "que el Congreso Nacional le dé a estos profesionales, por medio de un organismo netamente homeopático, la facultad de conocer y decidir acerca de sus propios asuntos, en vez de que siga confiando esa misión a sus enemigos" (Buitrago, 22 ene. 1953).

\section{NOTAS}

${ }^{1}$ En esta y en las demas citas literales de textos publicados en otros idiomas la traducción es libre.

2 “Tegua” es un gentilicio de la época precolombina. En tiempos de la conquista, los indios Tegua habitaban aún en Lengupá, en el Piedemonte llanero, Boyacá. Según algunos cronistas eran famosos por su arte de curar y sus conocimientos botánicos. Se constata la existencia de sus comunidades hasta el siglo XIX (Martínez Martín, 6 nov. 2017). A comienzos del siglo XX, renació el uso de la palabra con la figura de José Domingo Muñoz, campesino boyacense, curandero, natural de la vereda de Teguas, municipio de Macanal. Este mestizo llegó a Bogotá donde se hizo famoso. Publicó en 1906 y 1908 un folleto de defensa de su oficio titulado "El tegua" (Muñoz, 1908), título que se convirtió en su apelativo. La palabra se volvió de uso común en Bogotá y luego en toda Colombia, para nombrar a los sanadores sin diploma. Desde los años 1930, en la medicina universitaria, el término tiene una connotación peyorativa. 
${ }^{3}$ Ya se ha llamado la atención sobre la débil presencia de los médicos en el territorio nacional. En 1934, según el registro oficial, había 1.474 médicos, de los cuales 1.028 eran alópatas y 37 homeópatas diplomados; y 416 eran médicos permitidos, de los cuales 53 eran homeópatas (Colombia, 1935, p.242). En 1937, había 1.512 médicos registrados en el Departamento Nacional de Higiene para el territorio nacional, es decir un médico por cada 5.731 habitantes (Hernández, 2002, p.147).

${ }^{4}$ El liberalismo radical, llegado al poder en 1849, abolió las universidades, los títulos y grados universitarios y de bachiller (Nueva Granada, 24 mayo 1850).

${ }^{5}$ Aristides Acevedo y Luis Eduardo Acevedo, padre e hijo, presentan un memorial en 1930 para solicitar revalidación de sus licencias de homeópatas (Fondo..., 1905-1959, carpeta 3305). En la documentación incluyen declaraciones de otros homeópatas que certifican su idoneidad. Importa señalar que los expedientes de solicitud de revalidación de licencia de los certificantes, Antonio María Ortiz (Fondo..., 1905-1959, carpeta 3914), José E. Cubidez (Fondo..., 1905-1959, carpeta 3320) y Alfredo Aguirre P. (Fondo..., 1905-1959, carpeta 3302), se hallan en la misma sección "teguas". Se podía ser solicitante y recomendante al mismo tiempo.

${ }^{6}$ Manuel Sarmiento Castillo, director de la revista La Homeopatía.

${ }^{7}$ Fundada en 1894, órgano consultivo del gobierno, ley n.48 de 1898, ley n.55 de 1964.

${ }^{8}$ Casi todas las juntas departamentales de títulos médicos, creadas por la ley n.67 de 1920, reconocen en las licencias expedidas a los homeópatas permitidos el derecho de ejercer en toda Colombia. Aunque en algunos casos las licencias se otorgaban con limitación del ejercicio a un departamento o a uno o dos municipios. Esto suscitó conflictos de jurisdicción de la autoridad de las juntas y de los médicos graduados. Un ejemplo de ello es el caso de Diógenes Góngora (Fondo..., 1905-1959, carpeta 3333).

${ }^{9}$ En otro apartado de la carta se plantea la siguiente pregunta "Se debe movilizar la epidemiología para prevenir y combatir el principio de una epidemia de tifo o de tifoidea?" (Fondo..., 1905-1959, carpeta 3325, f.47)

\section{REFERENCIAS}

BOURDIEU, Pierre.

Elementos para una sociología del campo jurídico. In: Bourdieu, Pierre; Teubner, Gunther. La fuerza del derecho. Bogotá: Uniandes. p.153220. 2000.

BUITRAGO, Silvestre.

Atropellos de la Junta de Títulos Médicos. $\mathrm{La}$ Lucha Homeopática, p.1-2, 4. 22 ene. 1953.

BURNHAM, John C.

How the concept of profession evolved in the work of historians of medicine. Bulletin of the History of Medicine, v.70, n.1, p.1-24. 1996.

\section{COLOMBIA.}

Decreto n.2.597 de 1950, por el cual se dictan unas disposiciones reglamentarias del ejercicio de la medicina. Diario Oficial, p.613. 18 ago. 1950.

\section{COLOMBIA.}

Decreto n.2.736 de 1936, por el cual se reglamenta la ley n.67 de 1935 sobre ejercicio de la medicina. Diario Oficial, p.453. 18 nov. 1936.

\section{COLOMBIA.}

Departamento de Contraloría. Anuario general de estadística, 1934. Bogotá: Imprenta Nacional. 1935.

\section{COLOMBIA.}

Decreto $n .986$ de 1932, por el cual se adiciona y reforma el marcado con el n.1.099 de 1930. Diario Oficial, p.628. 11 jun. 1932.

\section{COLOMBIA.}

Consejo de Estado. Sentencia n.1.030 de octubre de 1931. Disponible en: <http://www.suin-juriscol. gov.co/clp/contenidos.dll/ConsejoEstado/300325 30 ?fn=document-frame.htm $\$ \mathrm{f}=$ templates $\$ 3.0>$. Acceso en: 15 abr. 2018. 1931.

COLOMBIA.

Decreto n.1.099 de 1930, por el cual se reglamenta la ley n.35 de 1929 sobre ejercicio de las profesiones médicas y algunas otras. Diario Oficial, p.99. 15 jul. 1930.

\section{COLOMBIA.}

Ley n.35 de 22 de noviembre de 1929 por la cual se reglamenta el ejercicio de la profesión de medicina en Colombia. Diario Oficial, p.537-539. 28 nov. 1929.

\section{COLOMBIA.}

Ley n.85 de 29 de noviembre de 1922 que reforma las que reglamentan el ejercicio de la profesión médica y sus auxiliares. Diario oficial, p.474-475. 5 dic. 1922 .

\section{COLOMBIA.}

Ley n.67 de 11 de noviembre de 1920 por la cual se reglamenta el ejercicio de la profesión médica. Diario Oficial, p.257-258. 11 nov. 1920.

\section{COLOMBIA.}

Ley n.83 de noviembre de 1914 por la cual se reglamenta el ejercicio de las profesiones médicas. Diario Oficial, p.1075-1077. 23 nov. 1914. 


\section{COLOMBIA.}

Decreto n.592 de 8 de junio de 1905 por el cual se reglamenta el ejercicio de la profesión de medicina. Diario Oficial, p.523-524. 19 jun. 1905.

\section{COLOMBIA}

Ley n.12 de 1905, por la cual se autoriza la reglamentación del ejercicio de la medicina y de la abogacía. Diario Oficial, p.317. 15 abr. 1905.

\section{EL CONSEJO..}

El Consejo de Estado falló a favor de los homeópatas. El Tiempo, p.4, 6 nov. 1931.

FAURE, Olivier.

L'homéopathie entre contestation et intégration. Actes de la Recherche en Sciences Sociales, n.143, p.88-96. 2002-2003.

\section{FONDO...}

Fondo Ministerio de Salud. Serie Teguas, cajas 219, 220, 221, 229, 232, 247, 259 (Archivo General de la Nación, Bogotá). 1905-1959.

FREIDSON, Eliot.

La teoría de las profesiones: estado del arte. Perfiles Educativos, v.23, n.93, p.28-43. 2001.

FREIDSON, Eliot.

La profesión médica. Barcelona: Península. 1978.

GUZMÁN, María del Pilar.

La alopatía y la homeopatía en el siglo XIX: conflicto entre dos prácticas médicas. Anuario Colombiano de Historia Social y de la Cultura, n.22, p.59-73. 1995.

HERNÁNDEZ, Mario.

La salud fragmentada en Colombia, 1910-1946. Bogotá: Unibiblos-Unal. 2002.

LÓPEZ, Alejandro.

La aldea y los doctores. Boletín Clínico, v.1, n.7, p.336-341. 1934.

LOS HOMEÓPATAS...

Los homeópatas obtienen un triunfo definitivo. El Tiempo, p.2. 9, dic. 1931.

MÁRQUEZ VALDERRAMA, Jorge.

El médico de oficio en Colombia en las décadas de 1920 y 1930. Revista Mundos do Trabalho, v.7, n.13, p.85-104. 2015.

\section{MÁRQUEZ VALDERRAMA, Jorge; ESTRADA} ORREGO, Victoria.

Culebrero, tegua, farmaceuta y dentista: el indio Rondín y la profesionalización médica en Colombia, 1912-1934. Anuario Colombiano de Historia Social y de la Cultura, v.45, n.1, p.79-104. 2018.

MÁRQUEZ VALDERRAMA, Jorge; GARCÍA, Víctor M.; DELVALLE MONTOYA, Piedad.
La profesión médica y el charlatanismo en Colombia en el cambio del siglo XIX al XX. Quipu, v.14, n.3, p.331-362. 2012.

MARTÍNEZ MARTÍN, Abel F.

El tegua. El Diario de la Salud. Disponible en: $<$ https://eldiariodesalud.com/catedra/el-tegua $>$. Acceso en: 22 oct. 2019. 6 nov. 2017.

MIRANDA, Néstor.

Historia social de la ciencia en Colombia:

la institucionalización de la medicina en Colombia. Bogotá: Colciencias. 1993.

MUÑOZ, José Domingo.

El tegua. Bogotá: Imprenta Americana. 1908.

NUEVA GRANADA.

Senado i Cámara de la Nueva Granada. Lei (de 15 de mayo de 1850) sobre instrucción pública. Gaceta Oficial, v.77, p.233-234. 24 mayo 1850.

PELLING, Margaret.

Managing uncertainty and privatising apprenticeship: status and relationships in english medicine, 1500-1900. Social History of Medicine, v.32, n.1, p.34-56. 2017.

QUEVEDO, Emilio et al.

Historia de la medicina en Colombia: hacia una profesión liberal, 1865-1918. Bogotá: Norma. 2010 .

QUEVEDO, Emilio et al.

Café y gusanos, mosquitos y petróleo: el tránsito de la higiene hacia la medicina tropical y la salud pública en Colombia, 1873-1953. Bogotá: Universidad Nacional de Colombia. 2004.

SÁNCHEZ LIÉVANO, Claudia.

Breve mirada al desarrollo de la historia de la homeopatía en el mundo durante los dos últimos siglos. Tesis (Maestría en Medicina Alternativa) - Universidad Nacional de Colombia, Bogotá. 2013.

SARMIENTO, Manuel.

Los homeópatas y la reglamentación de la medicina. El Tiempo, p.2. 1 ago. 1930.

SOLANO, Jairo.

Divulgación científica, medicina oficial y homeopatía en la epidemia de 1872 en Barraquilla. In: Márquez, Jorge; García, Víctor (Dir.). Poder y saber en la historia de la salud en Colombia. Medellín: Lealon. p.309-334. 2006.

TARCITANO, Conrado; WAISSE, Silvia. Novas evidências documentais para a história da homeopatia na América Latina: um estudo de caso sobre os vínculos entre Rio de Janeiro e Buenos Aires. História, Ciências, SaúdeManguinhos, v.23, n.3, p.779-798. 2016. 